\title{
Narco-Analysis Test
}

\section{Suresh Kumar}

\begin{abstract}
The term narco-analysis is used to define an investigative and psychotherapeutic method that practices psychotropic medicines, mainly barbiturates, to encourage a lethargy in which psychological essentials with strong related affects come to the superficial, where they can be abused by the psychotherapist. This test includes the venous administration of a medicine (such as sodium pentothal, \& sodium amytal) that reasons the issue to enter into numerous phases of anesthesia.

Keywords: Narco-Analysis Test.
\end{abstract}

\section{INTRODUCTION}

The word narco-analysis is used to define a problem-solving and psychotherapeutic method that procedures psychotropic medicines, mainly barbiturates, to persuade an inertness in which psychological fundamentals with solid related affects come to the external, wherever they can be abused by the psychiatrist. This test includes venous supervision of a medicine that reasons the matter to move in numerous phases of anesthesia. In the mesmerizing stage, the matter develops fewer self-conscious and is additional possible to disclose data, which would not normally be detected in the aware state-owned.

He may also manifest all his/her imaginations, individual requirements, instincts, primitive nature efforts, misbeliefs, fights, misunderstandings etc.

\section{OBJECTIVES}

1. To examination the Narco Analysis tests.

2. To inspect the psychological, bodily, social of this test?

3. Finds Demerits of Narco Analysis Test

\section{RESEARCH METHODOLOGY}

For this paper, both Primary and Secondary sources should be used. Primary sources were collected from research interview and personal observation. Secondary sources are collected from books, journal, internet etc.

\section{A. Meaning Narco Examination}

Etymologically the word narco-analysis is imitative from the Greek term 'Nark' meaning 'anesthesia' or 'torpor' and is used to define a investigative and psychotherapeutic method that procedures psychotropic drugs, particularly barbiturates, to induce a stupor in which mental elements with robust related touches come to the superficial, where they can be abused by the psychoanalyst.

Revised Manuscript Received on July 15, 2020.

Suresh Kumar*, Assistant Professor Law, IEC University Baddi Sciences Publication (BEIESP). This is an open access article under the CC BY-NC-ND license (http://creativecommons.org/licenses/by-nc-nd/4.0/)
* Correspondence Author Solan Himachal Pradesh, India. E-mail: lawsureshkr07@gmail.com

(c) The Authors. Published by Blue Eyes Intelligence Engineering and

The word 'narco-analysis' is a mixture of two words 'narco' and 'analysis' significance psycho examination, by supervision of medicines for encouraging a being to a situation of additional or fewer like sleep. A biological examination is performed on a person/doubtful where the person turns into a public of sleepy hypnotism, although the individual is subconsciously awakened with the aim of taking out the proofs from their subconscious awareness.

Hypnosis/semi-unconscious state follows as a consequence of sodium ingestion of pentothal/sodium amytal (medicines), directed on the individual, while queries are frequently focused at the being in that state, formulated for this determination. The procedure elaborate is identified as 'narco-analysis test.' The medicines have a mutual term called 'truth serum', but the scope of honesty to be found by the serum leftovers a arguable matter.

\section{B. First Narco Examination}

The use of these medicines was firstly proposed by Sir Arthur S. Lovenhart and his friends at "the University of Wisconsin in 1916", as one which could simplify message with expressively troubled patients.

Though these drugs were promoted by the trial of "Robert House, a Dallas Texas Obstetrician", one two doubts imprisoned in "Dallas County Jail in 1922", in his medicine helped interview, together males demanded to be blameless. And other term have similarly been used, such as "narco combination", "biological psychotherapy" and "psychological narco examination." Narco examination connecting the practice of the medicine scopolamine on offenders in the USA was first testified in 1922. Throughout and afterward the battle ages, USA militaries and intelligence organizations nonstop to experimentation with the certainty medicine and this has been nonstop by the Central Intelligence Agency.

The section drives more and Sir Robert House is smooth acknowledged to be the 'Father of Truth Serum.' An individual is capable to untruth by using his thoughts. In the Narco Examination experiment, the topic's thoughts are offset by manufacture him semi-conscious.

\section{Truth Drug Or Truth Serum}

The scientific tools of interrogation namely the narco study of the Truth Serum examinations are the principal three tests that have lately been established for removing acknowledgments. These psychoanalytical examinations are also used to understand the performance of the doubtful and verify the examining officer's interpretations.

This method of using medicines for the determination of inspecting is entitled "Narco-analysis test" also identified as the "Truth Serum Test." It resources psycho examination using drugs to encourage a state similar to sleep. Narcoanalysis examination is likewise recognized as "truth serum test."

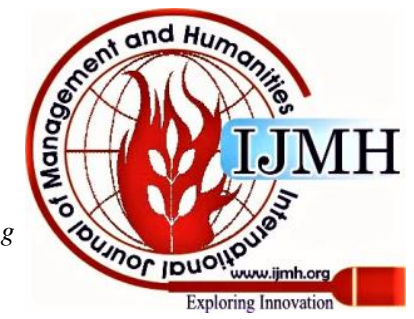




\section{Narco-Analysis Test}

They are the medicines occasionally used clinically.

\section{Sodium Pentothal}

Presently, the medicine used for narco investigation is entitled Sodium Pentothal and this occupation designation given by a corporation, Abbot Lab which exposed it in 1935. Its actual term is Thiopental Sodium, which is a thiobarbiturate, a portion of the barbiturate cluster of medicines.

But previously this developed the medicine excellent, surgeons responsibility narco examination for handling patients had numerous other medicines, hypnosis was also used in psychoanalysis. All these processes were calculated to assistance patients' misery from definite psychological diseases.

\section{E. Essentials for Conducting Narco Examination Test}

Staff Required: A Psychiatrist, An Anesthesiologist as General Physician, Forensic Psychologist, Supporting nursing staff, Audio videographer, Interpreter, if needed. Laboratory in India where Narco examination test done are: "Forensic Science Lab, Bangalore, Karnataka, Forensic Science Lab Gandhi Nagar, Gujarat."

\section{F. Procedure of Narco Examination Test}

Narco Analysis tests are directed in four stages: Pre Test Interview: Pre - Narcotic State Anesthetist induces narco and maintains the Pre narcotic state throughout the interview, Drug is injected till the person appears relax and instead of good conduct, Drug is given intravenously to induce hypnosis, As individual's speech starts slurring interview begins. Semi - Narcotic State: Forensic Psychologist facilitate the interview, Individual is allowed to sleep off and allow waking up on his/her off, Once he wakes up, anesthetist checks him/her and allows drinking coffee or tea, Complete Narco interview is audio video recorded and also written. Post - Test Interview: Memory is checked. Individual is allowed to know what he/she has spoken during interview.

Term Narco analysis is the first year in 1936 that the purpose of such drug administration is that under the influence of such medicine, the person is denied the authority of perceptive and self-discipline to talk freely and will not be capable to influence. The primary attitude is thus that when such power escapes, a person is assured to say the reality, using only his power of imagination that person can lie. In narco test the logic of the subject is neutralized and affected by making it half conscious.

Analysis of this country's current law enforcement system sheds light on the emergence of narco analysis as a technique that can aid criminal investigations. The increasing complexity of our society and the perceived diversity of the profiles of crimes committed in recent years have made the process of criminal investigation a difficult task in terms of obtaining appropriate or sufficient physical evidence.

Specific democratic nations, greatest particularly India, silent continue to use narco examination. It has come under growing condemnation from the community and the broadcasting in that nation. Narco examination is not acquiescently allowable for inspective determinations in most advanced and / or independent nations. The narco examination trial in India is performed by a group consisting of an anesthesiologist, a psychoanalyst; a scientific/medical psychologist, an audio videographer, and support treatment operate.

Scientific psychologists will make reports about the exposés, which will be made with a squeezed CD of audiovisual copies. The strong point of the disclosures, doubt essential, is not proved by the individual subject to further lie detector and brain mapping examinations.

Sodium Amytal interview technique was initially known in the diagnosis and was appointed to the treatment of mental illnesses and such narco-tips, narco-catharsis, narco-analysis and different callings as narco-synthesis.

The first narco examination was conducted in 2001 at the Bangalore FSL on a man connected with crimes committed by Veerappan._Intended for testing, the National Human Rights Commission prescribes definite rules to the consequence that testing should be managed only uncertainty the permission of the matter is acquired before a magistrate and therefore the police cannot conduct the test by them whenever they thought it appropriate. The practice of narco test in India is more or less a decade old, which began its use in investigations related to the Godhra massacre in the state of Gujarat in 20002, after a scam related to stamp paper orchestrated by Abdul Karim Telgi, who was on trial. Subject to. In 2005, in connection with a Mumbai serial bomb blast case, the accused had to undergo trial in 2007, in 2005, Imram @ Bilal was put to trial through a suspected terrorist. Charged in 2008 Malegaon bomb blast case underwent trial. The applicability of these cases led to their widespread publicity among the media and the general public, who were unaware of the process, the implications and dangers involved.

Narco examination is increasingly existence mainstreamed into examinations, courtyard trials, and labs in India. Narco examination came into the attention in the situation of the notorious Nithari rural community (Noida) serialized killings. The main blamed of the Nithari incident were two men, M.S. Pandher and S. Kohli (serial murder case) in Gandhinagar in Gujarat, with a narco analysis test. Narco analysis was used to interrogate the faulted in the twenty six November assaults in Mumbai by Ajmal Kasab. In the case of Aarushi's murder, the results of the narcoanalysis were acceptable in the courts but two years after the analysis; The Supreme Court of India called it unconstitutional but let investigators use the test results for clues.

\section{G. Demerits of Narco-Analysis Test}

Investigation are taking the aid of process narco-analysis test as an easy method of eliciting information with expectation of clues and leads, from suspects pertaining to their involvement in a crime, and doing away with time consuming and tolerance process of hunting for evidence. The investigators most of who do not come from medical background, are not aware of the evil consequences of hazards and dangers, in respect of administration of derivatives of Barbiturates which may at times prove fatal to the life of a suspect.

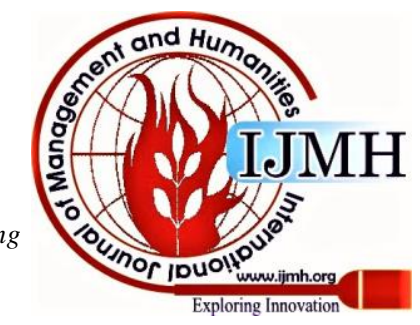


Prominent among the dangers in the context of medical reasons are: Damage of brain cells; perpetual damage of memory; perpetual state of misperception; Irreversible unconsciousness or death; permanent loss of all body activity; respiratory paralysis.

\section{CONCLUSION}

Examination is a scientific process for obtaining information from a person in a normal snooze like state and a being is responsible for falsehoods using his thoughts. In the narcoanalysis test, praying at the molecular level with its nervous system reduces the subject's barriers. In such a situation the determinations of the state are complete to acquire the actuality for proof nearby a sleeping crime. The accused in the case has been under judicial custody and with his consent was willing to undergo voluntary narco. With the help of a psychiatrist, forensic psychologist conducted narco analysis interview at the dispensary of Sabarmati Central Jail.

This technique cuts multiple ends, exposing disclosures can help investigators for important evidence or for corroborating preceding evidence and trial ideas. Narco examination test has also been used to identify mesmerizing phase matter is intentionally incompetent to overpower remembrances connected with related proofs. Therefore, it has been advised that medicine encouraged disclosures may assistance reduce investigative determinations thus redeemable community incomes. This sequence has an actual opportunity that the evidence removed complete such talks can top to the exposure of self-regulating proof that may be related. Consequently, we should reflect the consequence of such imitative use of encouraged medicine exposés, even if such revelations are not allowable as proof.

\section{REFERENCES}

1. Sarita Jand, Forensic Science \& Law 94 (New Eraw Publications, Faridabad, $1^{\text {st }}$ edn, 2017)

2. Dr. Nishant Singh, Forensic Science Principles and Applications 156 (Ancient Publishing House, Delhi, $1^{\text {st }}$ edn., 2011

3. Anoopam Modak, Scientific Techniques in Criminal Investigation 199 (Universal Law Publishing an imprint of LexisNexis, Gurgaon, 2016).

4. Criminal Law Journal 151 (2005).

5. R. Ramachandran, Scientific Techniques for Criminal Investigation 238 (Kamal Publishers, New Delhi, 2012).

6. Rajesh Punia, "Narco-Analysis Investigating Tool or a Torture?" 115 Criminal Law Journal 22 (2000)

7. Anoopam Modak, Scientific Techniques in Criminal Investigation 203 (Universal Law Publishing an imprint of LexisNexis, Gurgaon, 2016).

8. Prof. (Dr.) Kamal Jeet Singh and Vikram Singh, "Forensic Science: An Effective Tool in Criminal Justice Administration" 48 Civil \&Military Law Journal302 (2012).

9. Dr. (Mrs) Rukmani Krishnamurthy, Forensic Science in Criminal Investigation 526 (Selective \& Scientific Books, New Delhi, $1^{\text {st }}$ edn., 2011).

10. Prof. (Dr.) Vimala Veeraraghavan, Handbook of Forensic Psychology 110 (Selective \& Scientific Books, Delhi, $1^{\text {st }}$ edn., 2009).

11. B.B. Nanda \& Dr. R.K. Tewari, Forensic Science of India 236 (Select Publishers, New Delhi, 2001).

12. Bannur Mthai Mohan, \& Idquo; Misconceptions About NarcoAnalysis \& rdquo, available at: http://www.issuesinmedicalethics.org/151co07.html (Visited on September 25, 2019).

\section{AUTHORS PROFILE}

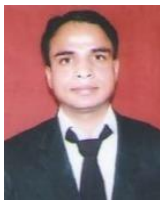

Suresh Kumar (LL.B. LL.M. UGC-NET, Pursuing PHD in Law) is an Assistant Professor in the Department of Law in IEC University Baddi Solan Himachal Pradesh. At Present, he has presented and published much research paper in various National and International Journals and Conferences.

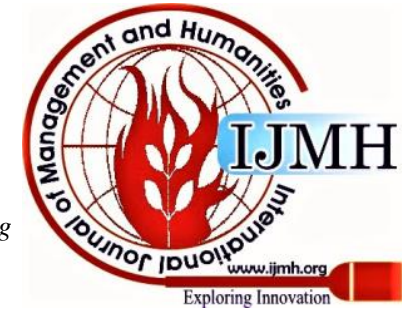

